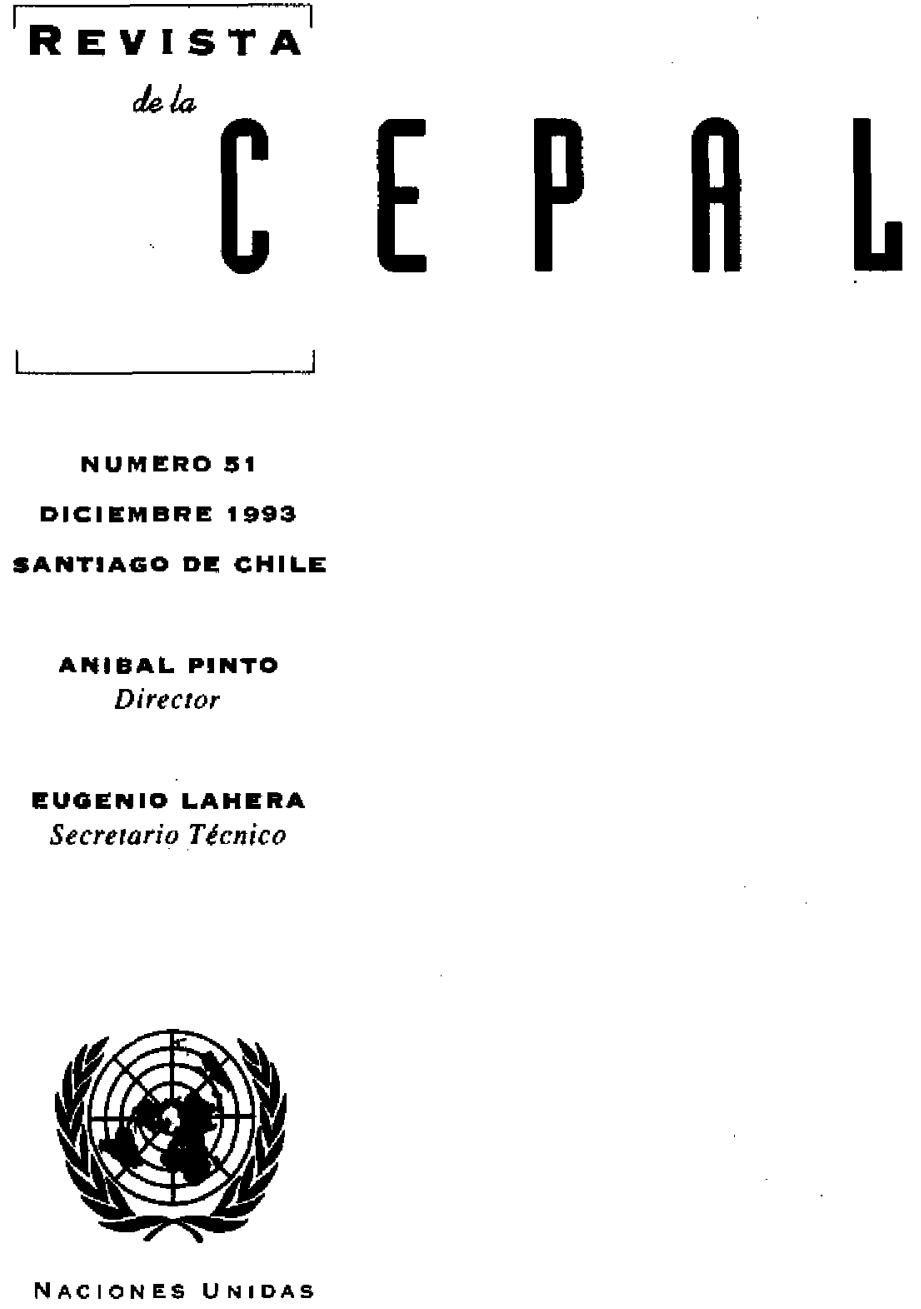


Inauguración de la Sala Fernando Fajnzylber y lanzamiento de la Revista de la CEPAL N² $\mathbf{5 0}$

Gert Rosenthal y Alejandro Foxley

Las transnacionales y la Industria en los paises en desarrollo

Michael Mortimore

¿Dónde estamos en política Industrial?

El desafío de la competitividad Industrial

Rudolf M. Buitelaar y Leonard Mertens

Integración y desintegración social rural

Martine Dirven

Los pueblos Indigenas y la modernidad

John Durston

Productividad y trabajo de la mujer en los Estados Unidos

Inés Bustillo y Nancy S. Barrett

Efectos de las corrientes de capltal sobre la base monetarla

111

Helmut Reisen

Viejas y nuevas políticas comerclales

Daniel Lederman

Integración y desviación de comerclo

Renato Baumann

Integración europea y comerclo latinoamericano

Miguel Izan

El actual debate sobre los recursos naturales

Fernando Sánchez Albavera

Orlentaclones para los colaboradores de la Revista de la CEPAL 


\section{Integración europea \\ y comercio latinoamericano}

\section{Miguel Izam}

Economista,

División de Comercio

Internacional, Transporte

y Financiamiento de la CEPAL.
Aunque es dificil prever con certeza la magnitud de los efectos que tendra el Mercado Unico Europeo (MUE) en el resto del mundo y en la propia Comunidad Europea ( $C E)$, la sensación predominante es de inquietud, particularmente en los países en desarrollo. En este artículo se busca determinar las consecuencias que podría tener el MUE en las exportaciones de América Latina a la CE, utilizando básicamente un enfoque analítico de corto y mediano plazo, ya que hay un conjunto de elementos que permiten anticipar con bastante certeza que la profundización de la integración comunitaria demorará más de lo previsto. Entre esos elementos destaca la necesidad de que la cE efectúe un ajuste económico, lo que exigirá mejorar la coordinación de las políticas macroeconómicas de sus países micmbros y resolver diversos problemas políticos de trascendencia, comenzando por la ratificación del Tratado de Maastricht. En todo caso, se admite la posibilidad de que en el largo plazo las implicaciones económicas del MUE para el resto del mundo, incluida América Latina, sean positivas. En la sección I del artículo se sef̃alan los efectos más probables que la profundización de la integración comunitaria provocaría en el corto y mediano plazo en la propia CE y en el resto del mundo; en la sección II se analiza el distanciamiento estructural que ha experimentado el vínculo comercial entre América Latina y los Doce en las últimas décadas, así como sus principales causas; $y$ en la sección III se reseñan las posibles consecuencias del MLE sobre el comercio de América Latina en el futuro previsible, las cuales, a diferencia de los efectos positivos que se podrían dar a largo plazo, no serían beneficiosas para esta región. 


\section{I \\ Efectos económicos del Mercado Unico Europeo en la Comunidad Europea y el resto del mundo}

\section{Beneficios económicos potenciales para la CE}

La base del MUE es el desmantelamiento de las fronteras físicas, técnicas y fiscales, lo que permitirá que las personas, bienes, servicios y capitales circulen libremente en el territorio comunitario. Hipotéticamente, tal desregulación provocará una mayor competitividad y obligará a los empresarios a reducir tanto los precios como los costos de producción. A su vez, la caída de los precios estimulará la demanda y, por lo tanto, aumentará la producción, lo cual disminuirá aún más los costos debido a las economías de escala. También se esperan beneficios por el uso de nuevas estrategias comerciales, el aumento de la eficiencia de las empresas al incorporar innovaciones tecnologicas y de gestión y la introducción de nuevos procesos productivos, todo ello estimulado por la dinámica propia del mercado interno.

El Informe Cecchini (Cecchini, 1988), encargado por la Comisión de las Comunidades Europeas, cuantificó los efectos de racionalizar los procedimientos aduaneros, las adquisiciones públicas y los servim cios financieros. Estim 6 que las mayores utilidades provendrían de la liberalización de este último mercado, ante lo cual se espera que los menores costos de los servicios financieros se transfieran a la economía en su conjunto. Así se reducirían los precios y aumentarian la demanda y la producción. A su vez, tal efecto favorable haría crecer la inversión como respuesta al costo del crédito.

Lo anterior generaría un crecimiento de $4.5 \%$ del producto interno bruto (PIB) de la CE, la creación de 1.8 millones de nuevos empleos, una reducción de $6.1 \%$ de los precios al consumidor, una mejora de las finanzas públicas de $2.2 \%$ del PIB y un aumento del saldo en la cuenta corriente de la $\mathrm{CE}$ equivalente a $1 \%$ del PIB. Sin embargo, el rango máximo del crecimiento del PIB comunitario se obtendría si los gobiernos de la CE adoptaran políticas fiscales

D El autor agradece los valiosos comentarios de Héctor Assael, Armando Di Filippo, Robert Devlin y Jan Heirman, así como el apoyo estadístico de Jaime Contador. más expansivas y gastaran todo el incremento que registrara el balance del sector público; en tal caso, el crecimiento del PIB subiría a cerca de $7.5 \%$, el número de nuevos empleos sería de 5.7 millones, los precios al por menor se reducirían en $4.3 \%$ y el saldo en cuenta corriente sería deficitario, equivalente a $0.5 \%$ del PIB. Los beneficios señalados en ambos escenarios se producirian en una sola oportunidad y se obtendrían a mediano plazo, cuatro o cinco años después de completado el MUE. ${ }^{1}$

\section{Algunas observaciones sobre el Informe Cecchinl}

Es importante precisar que los beneficios estimados en el Informe Cecchini están basados en una metodología que sólo considera los efectos económicos estáticos de la constitución del MUE. Por lo tanto, no cuantifica los efectos dinámicos del crecimiento. Al respecto, un estudio de Baldwin (1989) señala que tales beneficios serían relativamente equivatentes a aquellos proyectados por Cecchini. Sin embargo, las estimaciones de Baldwin han sido seriamente cuestionadas no sólo por su metodología, sino también porque si tales efectos existieran, únicamente se harían presentes en el largo plazo. ${ }^{2}$

Por su parte, también el Informe Cecchini ha sido objeto de fuertes críticas debido a que los beneficios que estima, incluso los más pesimistas, están basados sólo en los escenarios más favorables. Un argumento importante es que tal estudio no se refiere en profundidad al ajuste económico que necesariamente se produciría en las naciones comunitarias, ni a su intensidad y duración, como tampoco a los efectos adversos que éste podría tener en materia de desempleo. En principio, el mayor aprove-

\footnotetext{
I Cabe anotar que la metodología utilizada y las proyecciones realizadas en el Informe Ceochini sirvieron de base para un estudio dirigido por Emerson (1988), que también fue publicado oficial mente por la Comisión de las Comunidades Europeas (1988).

2 Véanse los comentarios de Pierre-André Chiappori y Anthony Venables, al final del artículo de Baldwin (1989).
} 
chamiento de las economías de escala se derivaría de una restructuración productiva que haría desaparecer una fracción no despreciable de las empresas comunitarias.

En este sentido, un estudio de Smith y Venables (1988) señala que probablemente la cantidad de empresas de la CE declinaría en todas las ramas de la industria, excepto dos, el cemento y las máquinas de oficina. El caso más dramático sería el del calzado, ya que desaparecerían 207 de las 739 firmas comunitarias. Una parte importante de estas pérdidas se concentraría en algunos países; por ejemplo, el Reino Unido perdería 46 de sus 65 empresas de calzado, 31 de sus 52 fábricas de alfombras y una de sus tres plantas de vehículos automotores. Por lo tanto, en el corto y mediano plazo el problema del desempleo podría agudizarse, lo cual provocaría presiones sociales y políticas que llevarían a incrementar el proteccionismo de la $\mathrm{CE}$. De otra manera, la absorción de los costos de la cesantía debería estar a cargo de los gobiernos mediante el pago de subsidios o a través de una política fiscal más expansiva, cuyo financiamiento tendría que provenir del sector privado, lo que generaría una tendencia al alza de la tasa de interés.

Otro ángulo de crítica a las proyecciones de los beneficios que figuran en el Informe Cecchini es que éste se escribio antes que se produjeran ciertos hechos históricos de extraordinaria importancia para el mundo y en particular para la CE. Entre otros, cabe destacar la reunificación alemana, los acontecimientos que están transformando profundamente a Europa central y oriental, la guerra del Golfo y la propuesta de la Iniciativa para las Américas. Por otra parte, también se aduce que una parte no despreciable de los beneficios que se esperaban al instaurarse el MUE ya se han obtenido gracias a fusiones, adquisiciones, alianzas e inversiones que han estado realizando numerosas empresas comunitarias en el espacio de la CE.

Todo lo anterior explica que la mayoría de los analistas económicos que han realizado estudios al respecto coincidan en señalar que el Informe Cecchini sobreestima los beneficios económicos que la $\mathrm{CE}$ obtendría como consecuencia de la instauración del MUE. Desde esa perspectiva, el Instituto de Relaciones Europeo-Latinoamericanas (IRELA, 1991, p. 19) plantea que "varios estudios no oficiales han evaluado la aceleración en el crecimiento en sólo un $1.5 \%$ a $2.5 \%$ ". A modo de ilustración, cabe indicar que Peck $(1989$, p. 289$)$ afirma que las ventajas económicas se elevarían a sólo un $2 \%$ del PIB de los países comunitarios.

\section{Perspectivas probables para el resto del mundo}

Desde un punto de vista sistémico, sólo es posible entender el MUE situándolo en su contexto histórico global. Por un lado, este avance programático otorga mayor profundidad al modelo más evolucionado de integración regional que existe. Por otro, es imperativo que la $\mathrm{CE}$ logre mejorar su capacidad tecnológica a fin de elevar su competitividad internacional en algunos sectores, en particular para alinearse con los Estados Unidos, Japón y los países de reciente industrialización (CEPAL, 1990a). En consecuencia, más allá de la retórica y las declaraciones de intención, las motivaciones que la $\mathrm{CE}$ ha tenido para dar forma al MUE responden evidentemente a necesidades internas vinculadas a su propio desarrollo. Así, el impacto económico que el MUE genere sobre el resto del mundo es un factor que estará basado principalmente en cómo evoluciona la dinámica comunitaria.

Es difícil poner en duda que el MuE provocará consecuencias económicas negativas para el resto del mundo, al menos en el corto y mediano plazo. Tal planteamiento se fundamenta en que obviamente la eliminación de las barreras intemas tiene por objeto incrementar la demanda comunitaria de bienes y servicios producidos en su territorio, cuyos precios serán menores comparados con los anteriores al MUE y con los de las importaciones extracomunitarias. De hecho, toda la formulación metodológica en que se basa el Informe Cecchini está fundada en ese argumento. Además, la Comisión de las Comunidades Europeas (1989) ha señalado explícitamente que espera que el MUE siga estimulando la tendencia ascendente que ha experimentado el coeficiente de las importaciones intracomunitarias con respecto a las importaciones totales que ha realizado la $\mathrm{CE}^{3}$

Por lo tanto, es evidente que se producirá una desviación de las importaciones provenientes del resto del mundo, cuya magnitud, ceteris paribus, dependerá principalmente de la elasticidad-precio de la demanda de la CE. La Comision de las Comunidades

\footnotetext{
${ }^{3}$ En 1963 el comercio intracomunitario de bienes representaba el $48 \%$ del intercambio total de la CE (Comisión de las Comunidades Europeas, 1989). En cambio, a principios de la década de 1980 . este coeficiente superaba el $50 \%$ y para 1991 rayaba el $62 \%$ (Comisión de las Comunidades Europeas, 1992, p. III).
} 
Europeas (1988) estima que las importaciones extracomunitarias se reducirían entre $7.9 \%$ y $10.3 \%$. Cabe señalar que es imposible que este efecto se vea compensado por la subsiguiente creación de comercio que se produciría como consecuencia del crecimiento adicional que experimentaría la CE. En el supuesto de un comportamiento lineal, si es correcto el generoso cálculo de que el PIB de la CE aumentará $4 \%$, se produciría un incremento de sólo $0.4 \%$ de las importaciones extracomunitarias, debido a que el coeficiente de éstas con respecto al producto es algo menor al $10 \%$.

En definitiva, desde una perspectiva optimista en que el crecimiento adicional de la CE asciende a $4 \%$ y la reducción de las importaciones extracomunitarias no supera el $7.9 \%$, las exportaciones del resto del mundo dirigidas a la CE experimentarán una caída de $7.5 \%$. Por lo tanto, el efecto comercial neto para las economías no comunitarias será, en términos generales, negativo. Más aún, dados otros factores, se podría pensar que los costos comerciales para el resto del mundo serán muy superiores a esa estimación.

En efecto, uno de los elementos que debe considerarse es que las exportaciones de la $\mathrm{CE}$ a terceros mercados serán relativamente más competitivas, con lo cual desplazarán a las exportaciones de los demás países del mundo, desviando así una parte de su comercio que será necesario estimar. Otra línea de argumentación en ese mismo sentido tiene que ver con la jerarquía de preferencias de la $\mathrm{CE}$, tema que por su importancia para América Latina será analizado más adelante. No obstante, cabe adelantar que ciertas regiones del resto del mundo quizá deban enfrentar costos económicos importantes, aunque diferenciados, debido especialmente a que la creación del Espacio Económico Europeo fomentará el comercio entre los Doce y los países miembros de la Asociación Europea de Libre Intercambio (AELI), organismo que ya es el principal socio comercial de la $\mathrm{CE}^{4}$

Otra fuente de argumentos que hace prever efectos adversos para el resto del mundo tiene que ver con las economías de escala. Si la CE puede alcanzar operaciones de escala mínimamente eficientes por sí mismas, las limitaciones a las importaciones extracomunitarias parecen ser una contrapartida natural (Dornbusch, 1989). Entre otros factores, ello explica que un gran número de empresas transnacionales esté reasignando inversiones hacia territorio comunitario,

${ }^{4}$ La AELI es responsable de thás de $20 \%$ del comercio extrarregional de la $\mathrm{CE}$. como una forma de anticiparse a las consecuencias negativas que el MUE podría generarles. Entre 1981 y 1983 un $15 \%$ de la inversión extranjera directa de los Estados Unidos tuvo por destino la $\mathrm{CE}$, mientras que entre 1984 y 1987 tal proporción se elevó a $55 \%$. Durante esos años el mismo indicador para Japón subió de $10 \%$ a $17 \%$ (CET, 1989).

Luego, todo lo anterior permite afirmat que el MUE generará, de manera implícita y por su propia naturaleza, consecuencias económicas adversas para el resto del mundo. ${ }^{5}$ Entonces, la pregunta que cabe formular no es si el MUE provocará efectos negativos sobre el resto del mundo, sino cuál será la magnitud de tales impactos. Tampoco tiene sentido preguntarse si las barreras internas que se eliminarán serán trasladadas a las fronteras de la $C E$, ya que, según se vio, esto no es necesario para que se estructure un "castillo europeo", es decir, un escenario que tendría consecuencias económicas negativas para el resto del mundo, aunque la CE no aplicara consciente y deliberadamente una política económica expresa a tal efecto, como lo haría en el caso de una "fortaleza europea".

De cualquier modo, como ya se observó, todo parece indicar que será ineludible que la CE enfrente la necesidad de ajustar su economía en el proceso de estructuración del MUE, al menos en el corto y mediano plazo. Así, es posible prever un incremento del desempleo como consecuencia del mayor nivel de competitividad que generaría la libre circulación de bienes y servicios en todo el espacio comunitario. Ello podría provocar la aplicación de una política fiscal expansiva -lo cual sería perfectamente coherente con la "dimensión social" del proyecto de los Doceque elevaría la tasa de interés, con el consiguiente perjuicio para los países en desarrollo, particularmente aquellos que tienen niveles altos de endeudamiento externo.

Tampoco sería descartable la aplicación de una política comercial complementaria que contribuya a agudizar el proteccionismo comunitario. ${ }^{6}$ En este escenario sí podría hablarse de una "fortaleza europea",

\footnotetext{
5 Además de todas las razones expuestas anteriormente, se sabe que como consecuencia del MUE la CE aplicará ciertas normas técnicas a sus importaciones, lo cual también dificultará el acceso de las exportaciones del resto del mundo a ese mercado, como se examinará más adelante.

6 Proteccionismo que incluso podría apoyarse con una aplicación discriminatoria y poco transparente de las nuevas normas tecnicas al comercio de la CE, cuestión que se analiza en la última sección de este artículo.
} 
en el sentido de que el "castillo de los Doce" serfa defendido de manera explícita y consciente del resto del mundo, disparando "proyectiles" de política económica, particularmente de política comercial, de un calibre que hoy sería imposible precisar, pero que afectaría de manera muy especial a los países en desarrollo, ${ }^{7}$ sobre todo porque no hay duda de que la capacidad de aplicar represalias comerciales y de negociar de la CE será más poderosa en la medida en que todas sus disposiciones comerciales estén centralizadas. Además, cabe anotar que la gravitación de los países en desarrollo en el comercio de la CE se ha reducido sistemáticamente en los últimos años. Sólo en la década de los ochenta la importancia de estas naciones ha caído de $20 \%$ a $13 \%$ del comercio comunitario. En cambio, la participación de los países de- sarrollados en el comercio de la $\mathrm{CE}$ ha subido de $76 \%$ a $84 \%$ en el mismo periodo. ${ }^{8}$

Pese a todo lo anterior, la CE se esfuerza en mostrar que el MUE tendrá consecuencias benéficas para ella y para el resto del mundo, porque constituiría un gran movimiento de desregulación y liberalización económica que generaría un entorno económico internacional más competitivo. No obstante, e incluso admitiendo que ello fuera cierto en el largo plazo, es difícil encontrar consecuencia entre tal afirmación y el hecho de que la $\mathrm{CE}$ ha sido uno de los principales obstáculos para el pronto y feliz término de la Ronda Uruguay del Acuerdo General sobre Aranceles Aduaneros y Comercio (GATT), lo que sin duda sí entrañaría un notable progreso en el funcionamiento del sistema multilateral de comercio.

\section{II}

\section{Distanciamiento en las relaciones comerciales} entre América Latina y la $\mathrm{CE}^{9}$

La CE es el mayor bloque comercial del mundo, no sólo considerando su comercio total sino también sus transacciones extracomunitarias de bienes. ${ }^{10}$ No obstante, desde 1975 dejó de ser el principal mercado para las exportaciones latinoamericanas de bienes. En efecto, en 1970 la CE absorbía más de $33 \%$ de las exportaciones de América Latina, superando a los Estados Unidos, que tenían una participación de sólo $28 \%$. Tal orden se revirtio a mediados de esa década, pasando éste a ser el primer destinatario de las colocaciones externas de la región, tendencia que se acentuó posteriormente. Así, en 1990 la CE se hizo cargo de sólo $24 \%$ de las exportaciones latinoamericanas, mientras que las que tuvieron por destino los Estados Unidos eran el 36\%. ${ }^{11}$ Por otro lado, también la CE ha perdido importancia como proveedora de las importa-

\footnotetext{
7 Luego, el punto de vista que se sostiene en este artículo coincide con Emmerij (1990, pp. 248 y 249), que señala que "en suma, en lo que respecta a la desviación frente a la creación del comercio, entiendo que para los países en desarrollo los peligros son mayores que las oportunidades".

8 La participación complementaria está cxplicada por el comercio con Europa central y oriental, según datos extraídos del United $\mathrm{Na}$ tions Monthly Bulletin of Statistics, Nueva York, varios números.

${ }^{9}$ Los antecedentes estadísticos relativos al comercio entre América Latina y la $\mathrm{CE}$, cuya fuente no se explicita, fueron sistematizados por el autor a base de datos suministrados por la CEPAL.
}

ciones de América Latina. En 1970, más de un cuarto de las compras que estos países realizaron desde el exterior era de origen comunitario; en 1990, sólo $19 \%$ tenía esa procedencia.

El fenómeno anterior se acentúa cuando se observa la evolución que ha experimentado la importancia de América Latina para el comercio de la CE. En 1965 la región latinoamericana absorbía $6.1 \%$ de las exportaciones extracomunitarias y suministraba $9 \%$ de las importaciones externas de los Doce. En 1990, tales participaciones cayeron a $3.4 \%$ y $5.2 \%$, respectivamente. Por lo tanto, se ha producido un distanciamiento estructural en la relación comercial entre ambas regiones, caracterizado por una virtual marginación de América Latina del circuito europeo de transacciones de bienes.

Es fundamental agregar que el comercio no es la

\footnotetext{
10 En 1990 la participación de sus transacciones totales de bienes en el comercio mundial fue de casi $38 \%$, y de $20 \%$ si se consideran sólo las transacciones extracomunitarias de bienes (CEPAL, 1992a). 11 Es interesante sef́alar que siempre que se considera a Amćrica Latina en su conjunto se esconden las grandes diferencias que existen entre los paises que la componen. Por ejemplo, Ecuador es el país latinoamericano para el cual el mercado de la CE es el menos importante ( $10 \%)$; el caso opuesto es el de Chile (37\%), donde la gravitación comunitaria incluso supera a la de los Estados Unidos $(17 \%)$
} 
única esfera en que la relación económica entre la CE y América Latina se ha debilitado en las últimas décadas. Un proceso similar se ha producido en el ámbito financiero, particularmente en la inversión extranjera directa. Asimismo, la asistencia oficial para el desarrollo que ha recibido América Latina no es muy significativa en proporción al aporte comunitario total al mundo en desarrollo (Izam, 1991). Todo lo cual se contradice curiosamente con el notable estrechamiento de los vínculos políticos entre América Latina y la CE (CEPAL, 1990b).

La responsabilidad del distanciamiento económico estructural que se verifica entre América Latina y la $C E$ no puede atribuirse de manera exclusiva a ninguna de las partes. De hecho, en los últimos veinte años América Latina ha vivido un proceso de virtual marginación de los flujos mundiales, tanto de exportaciones como de importaciones de bienes. ${ }^{12} \mathrm{Tal}$ fenómeno se explica en buena medida porque su estructura exportadora no ha evolucionado armónicamente con los cambios dinámicos que se han producido en la demanda internacional. ${ }^{13}$

Así pues, aun cuando la participación de las manufacturas en las exportaciones latinoamericanas al mundo ya es de $34 \%$, coeficiente notable comparado con el $9 \%$ correspondiente a 1970 , todavía sus economías son preponderantemente primario-exportadoras, aunque se observan diferencias apreciables entre ellas. ${ }^{14}$ Luego, los países de América Latina deben hacerse cargo de esta realidad y orientar sus economías hacia un proceso de transformación productiva sustentado en una incorporación deliberada y sistemática de progreso técnico, con miras a lograr una creciente competitividad internacional (CEPAL, 1990c y 1992c).

En consecuencia, la estructura de las exportaciones latinoamericanas a la $\mathrm{CE}$ se ha concentrado altamente en los productos básicos. En 1970,61\% de ese flujo total consistía en alimentos y materias primas agrícolas, en tanto que el conjunto de los bienes no manufacturados constituía el $95 \%$. En 1990, tales bienes redujeron su participación a $77 \%$, mientras que los productos agrícolas disminuyeron su importancia

12 El coeficiente de las exportaciones se redujo de $4 \%$ a $3.2 \%$, mientras que el de las importaciones bajó de $3.8 \%$ a $2.7 \%$.

${ }^{13}$ Otra razón muy importante tiene que ver con las dificultades de acceso de las exportaciones de la región a los mercados internacionales.

14 Por ejemplo, para Brasil las manufacturas representan más de $50 \%$ de sus exportaciones totales, mientras que para Ecuador no equivalen siquicra a $2 \%$. a $42 \%$. Por lo tanto, más de dos quintos de las colocaciones de bienes de América Latina en la CE tropiezan todavía con problemas de acceso a ese mercado, derivados principalmente, aunque no de manera exclusiva, de la aplicación de la Política Agrícola Común (PAC) de la Comunidad.

En los últimos veinte años las manufacturas aumentaron de $5 \%$ a $23 \%$ su ponderación dentro de las exportaciones de bienes de América Latina a la $\mathrm{CE}$. Sin embargo, es preciso hacer una salvedad. La participación de las manufacturas en las exportaciones latinoamericanas a la CE era similar a la de aquellas destinadas al mercado de los Estados Unidos en 1980 , ambas cercanas al $12 \%$. En cambio, en 1990, las manufacturas constituían el $35 \%$ de las exportaciones latinoamericanas a ese país, ${ }^{15}$ mientras que las dirigidas a la Comunidad no llegaban siquiera a $23 \%$, coeficiente que ese mismo año era ampliamente superado por la presencia de las manufacturas en las exportaciones totales de América Latina al mundo que, como ya se indicó, alcanzaba al $34 \%$. En consecuencia, la $\mathrm{CE}$ ha perdido importancia como mercado en el total de las exportaciones de manufacturas latinoamericanas. En efecto, su participación cayó de $17 \%$ a $14 \%$ entre 1970 y 1990.

No es posible explicar cabalmente la magnitud de esta reducción, aduciendo simplemente que las exportaciones manufactureras latinoamericanas han quedado rezagadas en relación al desempeño que en este ámbito han registrado los países de industrialización reciente de Asia, ni señalando que las manufacturas que América Latina coloca en la $\mathrm{CE}$ enfrentan demandas decrecientes en ese mercado. Objetivamente, una parte importante de esas exportaciones esta sujeta a distintas medidas proteccionistas que dificul$\tan$ su penetración en el territorio comunitario. En suma, como se analiza a continuación, tanto las colocaciones latinoamericanas de bienes primarios como las de productos manufacturados tropiezan con barreras arancelarias y no arancelarias en su acceso al mercado de la CE.

\section{Barreras arancelarlas a las Importaclones do la CE}

El promedio de los aranceles aplicados por la CE a las importaciones procedentes de los países miembros del

\footnotetext{
${ }^{15}$ Es importante aclarar que las cifras utilizadas para las exportaciones de América Latina a los Estados Unidos no incluyen las transacciones vinculadas a la industria maquiladora.
} 
GATT es sólo cercano al 5\%. No obstante, ese bajo coeficiente oculta la protección arancelaria que la $\mathrm{CE}$ aplica a actividades productivas que tienen un mayor valor agregado. Así, se penaliza a ciertas exportaciones latinoamericanas, particularmente manufacturas, dificultándoles el acceso al mercado comunitario con aranceles que aumentan proporcionalmente según el grado de elaboración del producto. Un ejemplo ilustrativo de la progresividad arancelaria de la Comunidad es el de la exportacion chilena de tomates a ese mercado; cuando son frescos pagan un arancel de $3 \%$, mientras que la pasta de tomate está sujeta a una tasa de $18 \%$ (Sáez, 1992).

Cabe destacar que la $\mathrm{CE}$ aplica la progresividad arancelaria a una parte muy sustantiva de sus importaciones de manufacturas. Más aún, en varios sectores económicos este tipo de proteccionismo es más restrictivo en ese mercado que en los Estados Unidos y en Japón. Se trata, entre otros productos, de las cadenas productivas de la carne, los vegetales, los aceites vegetales, el papel, el plomo, el zinc y el petróleo, todos los cuales tienen una importancia vital en las exportaciones de América Latina a los Doce (Butelmann y Campero, 1992). Por lo tanto, la estructura arancelaria de la $\mathrm{CE}$ distorsiona la competitividad de los productos más elaborados que la región latinoamericana coloca en ese mercado, no sólo haciendo más difícil su acceso sino a menudo también impidiéndolo.

\section{Barreras no arancelarias a las importaciones de la $\mathrm{CE}^{16}$}

En el sector agrícola, la mayoría de las barreras no arancelarias (BNA) se aplica en el marco de la PAC, afectando a cultivos de clima templado, incluido el azúcar, que constituyen casi tres cuartos del valor de las importaciones agrícolas de la $\mathrm{CE}^{17}$ Tales medidas afectan no sólo a productos agrícolas en estado más primario, como las frutas, las legumbres, las semillas, el pescado y la carne, sino también a ciertos bienes más elaborados, como el vino. Aparte la PAC, también se aplican límites cuantitativos a las exportaciones de

\footnotetext{
16 Los datos estadísticos correspondientes a las barreras no arancelarias fueron tomados de CEPAL, 1992b. Cabe señalar que los coeficientes de cobertura que se mencionan en el texto implican que al menos se aplica una barrera no arancelaria en el mercado de acceso de las exportaciones latinoamericanas.

17 Las medidas más utilizadas son los derechos variables, los precios de referencia y las restricciones voluntarias a las exportaciones.
}

algunos productos tropicales como el banano, para reservar un acceso preferente a las exportaciones de países del Caribe y de Africa. En definitiva, más de una cuarta parte del valor de los alimentos exportados por América Latina a la CE tropieza con barreras no arancelarias.

También las manufacturas están sujetas a distintas barreras de esa índole en su acceso a la CE. ${ }^{18}$ Excluyendo los productos químicos, $26 \%$ del valor total de las manufacturas latinoamericanas exportadas a la CE enfrenta barreras no arancelarias en ese mercado. Entre otros bienes, los más afectados son los textiles, las prendas de vestir y el calzado, en un $90 \%, 55 \%$ y $99 \%$ de su valor, respectivamente.

Además de los sectores seffalados, cabe destacar la alta cobertura de esas barreras en otros dos rubros de interés para la exportación latinoamericana a los Doce. Se trata de los combustibles y el hierro y el acero, para los cuales tales medidas proteccionistas afectan a $44 \%$ y $92 \%$ de sus respectivas exportaciones a la CE. En suma, $22 \%$ del valor total de las exportaciones de bienes de América Latina a la CE enfrenta barreras no arancelarias en su acceso a ese mercado, las cuales afectan relativamente más a las manufacturas que a los alimentos y productos agrícolas.

Cabe consignar que, en materia de protección no arancelaria, las exportaciones latinoamericanas enfrentan más problemas en el mercado comunitario que en los Estados Unidos y Japón. En efecto, las barreras no arancelarias comprometen sólo $13 \%$ de las colocaciones de bienes de America Latina en cada uno de estos dos últimos mercados. Más aún, la protección no arancelaria de la CE es sistemáticamente superior a la estadounidense y a la japonesa para las exportaciones latinoamericanas de combustibles, hierro y acero y manufacturas, excluidos los productos químicos, y en materia de alimentos, la de Japón supera a la comunitaria, y ésta a la de Estados Unidos.

En términos de magnitud, la gran heterogeneidad de América Latina hace que las consecuencias de las barreras no arancelarias que aplica la $\mathrm{CE}$ sean muy diferentes para cada uno de los países latinoamericanos. Estos efectos varían en función de la composición y del valor total de sus distintos rubros

\footnotetext{
${ }^{18}$ Los instrumentos de uso más frecuente son los límites cuantitativos, las medidas de vigilancia, las licencias, los contingentes, las restricciones voluntarias a las exportaciones $y$ las medidas antidumping, compensatorias y de salvaguardia.
} 
de exportación a la $\mathrm{CE}^{19}$ y de la distribución sectorial de dichas barreras en ese mercado. Así pues, tomando en cuenta el coeficiente de cobertura de las barreras no arancelarias a las exportaciones totales de cada uno de los países a la $\mathrm{CE}$, los más perjudicados son México (52\%), Uruguay (47\%), Ecuador (29\%), Argentina (28\%), Costa Rica (20\%) y Honduras $(20 \%) .{ }^{20}$ En cambio, los efectos son prácticamente nulos para Nicaragua $(2.4 \%)$, Bolivia $(0.1 \%)$ y El Salvador $(0.1 \%)$, lo que indica que las repercusiones que podría tener en América Latina el funcionamiento del MUE serán muy diferentes en cada uno de los países de la región.

En conclusión, el proteccionismo de la CE es responsable, por un lado, de gran parte del distanciamiento comercial registrado con América Latina tanto en productos básicos como en bienes industrializados $\mathrm{y}$, por otro, de que la participación de las manufacturas en la composición de las exportaciones latinoamericanas a ese mercado sea todavía muy reduci$\mathrm{da}$, e incluso notablemente inferior a la presencia de estos productos en las colocaciones externas totales de América Latina. Todo lo anterior parece indicar que América Latina no ocupa un lugar importante en la jerarquía de preferencias de la $\mathrm{CE}$.

\section{Jerarquía de preferencias de la CE}

La CE pretende en primer lugar estrechar aún más sus vínculos con los países miembros de la AELI (Delors, 1991). Al mismo tiempo, como resultado de los procesos de reforma político-económica que se desarrollan en Europa central y oriental, la CE debe redefinir su relación con esos países, tanto por razones económico-sociales como por causas geopolíticas. De hecho, en la actualidad está proliferando una serie de negociaciones comerciales entre los Doce y casi todas esas naciones, varias de las cuales ya disfrutan de las ventajas comerciales de los acuerdos de asocia-

${ }^{19}$ Sólo cuatro países originan casi el $80 \%$ de las exportaciones de América Latina a la cE. Se trata de Brasil (38\%), Argentina (14\%), México (13\%) y Chile (12\%). La concentración en las manufacturas es mayor aún. Tres países, Brasil, Argentina y México, dan cuenta de cerca de $85 \%$ del total de las exportaciones latinoamericanas a la $\mathrm{CE}$.

${ }^{20}$ México principalmente por el petróleo, Uruguay por los alimentos y los textiles, Ecuador por los alimentos y las prendas de vestir, Brasil por los alimentos, la siderurgia y el calzado, Argentina y Chile por los alimentos. Por su parte, los productos tropicales, particularmente el banano, tienen una gran incidencia para países centroamericanos como Costa Rica, Honduras y Guatemala, al igual que para Colombia y Ecuador. ción o se acogen al Sistema Generalizado de Preferencias (SGP).

En cuanto al mundo en desarrollo, los países que tienen primera prioridad son los de Africa, el Caribe y el Pacífico (ACP), adscritos a la Convención de Lomé. Se trata de ex colonias de paises europeos, a las que la CE ofrece ventajas comerciales, institucionales y de ayuda al desarrollo. Entre las ventajas comerciales figura el libre acceso de los bienes industriales y de la mayoría de los productos agrícolas tropicales, algunos de los cuales incluso compiten con la propia producción comunitaria, como en el caso del azúcar.

La segunda preferencia la tienen los países ribereños del Mediterráneo que han concertado con la $\mathrm{CE}$ acuerdos de cooperación comercial y para el desarroIlo. En estos acuerdos se estipulan franquicias aduaneras para los productos industriales, excepto los textiles. Los productos agrícolas que compiten con la producción comunitaria protegida por la PAC están sometidos a contingentes, en el marco de los cuales quedan parcialmente exentos de aranceles. Es importante señalar que varios de estos países han solicitado su incorporación a la CE. ${ }^{21}$

También la CE manifiesta un gran interés en los países árabes del Golfo Pérsico, esencialmente por su dependencia energética de esa región del mundo. Concretamente, la CE ha buscado ampliar los acuerdos comerciales vigentes a fin de abarcar cuestiones de colaboración comercial, transferencia de tecnología, incentivos a las inversiones, desarrollo de la agricultura y demás asuntos relacionados con la cooperación para el desarrollo.

El último lugar de prioridad corresponde a los países asiáticos y latinoamericanos, que sólo cuentan con las ventajas que les otorga el SGP. ${ }^{22}$ No obstante, es importante mencionar que, en el caso de América Latina, tal Sistema no ha logrado producir los beneficios que se esperaban, pese a que éstos aumentaron de manera considerable en los años ochenta. En 1980 el $10 \%$ de las exportaciones latinoamericanas a la CE ingresó bajo el SGP; en

\footnotetext{
21 Se trata de Chipre, Malta, Marruecos y Turquía.

22 Es importante destacar que aparte del SGP que la CE concede por igual al conjunto de la región latinoamericana, algunas naciones reciben un trato especial cuyos beneficios son mayores que los derivados del sistema comín. Sin embargo, estas preferencias tienen un carácter transitorio y sus ventajas no son comparables con los beneficios que reciben los páses ACP. Cabe citar el caso de las naciones andinas, que gozan de esos beneficios como una forma de estimular la producción de cultivos distintos de la cosa.
} 
1988, tal cobertura ascendió a 20\% (IRELA, 1992). Por ciertas características del SGP, los países de América Latina que se han beneficiado en mayor medida son aquellos cuya producción está más diversificada y que tienen redes comerciales bien establecidas, como es el caso de Brasil y, en menor grado, de Argentina y Chile.

Varias razones explican el escaso aprovechamiento latinoamericano del SGP de la CE. Primero, la gran mayoría de los productos agrícolas están excluidos del Sistema, debido a que su ingreso afectaría a la economía de los Doce, por lo cual son considerados productos "sensibles". Ello impide que una parte importante de las exportaciones de América Latina a la CE goce de las ventajas del SGP comunitario. Segundo, también se señala en el medio comercial latinoamericano la falta de transparencia y coherencia del SGP; que dificulta considerablemente su utilización eficaz y causa problemas en su aplicación; en particular, las concesiones sólo se otorgan por solicitud, lo que tiende a favorecer a los países que poseen más experiencia y dinamismo exportador, como algunas naciones asiáticas.

Se espera que en el futuro la CE reformule el SGP, otorgándole mayor estabilidad y flexibilizando las normas de origen, y abra la posibilidad de dar un trato acumulativo a nivel regional o subregional, to cual, por una parte, facilitaría el acceso de las exportaciones latinoamericanas a la $\mathrm{CE}$ y, por otra, incentivaría la integración económica de esa región (SELA, 1992). Sin embargo, "las posibilidades de que el SGP tenga un efecto significativo sobre la actual situación en los años venideros son remotas" (IRELA, 1992, p. 28).

Todo lo anterior permite coincidir con la opinión de un presidente del Parlamento Europeo: "para decirlo con mucha dureza, América Latina nunca ha estado en el punto de mira de Europa" (Barón, 1991, p. 95). Por lo tanto, lo más probable es que América Latina siga siendo una región geográfica en la que la $\mathrm{CE}$ tenga poco interés económico, más allá de que se prođuzcan algunos progresos a través de las distintas instancias de diálogo que existen entre los Doce y América Latina. ${ }^{23}$

\section{III}

\section{Efectos del Mercado Unico Europeo sobre el comercio de América Latina}

\section{Efectos generales}

En consecuencia, los efectos del MUE sobre el comercio de los países latinoamericanos serán, en términos globales, más negativos que para el resto del mundo, debido principalmente al proceso histórico de desvinculación económica producido entre América Latina y la $\mathrm{CE}$, fenómeno en el que ambas partes tienen responsabilidad, aunque no necesariamente en la misma medida, y al escaso interés que los Doce han mostrado por esa región en desarrollo. No puede precisarse la magnitud del costo comercial para América Latina, por cuanto éste dependerá básicamente, por un lado, de la capacidad de respuesta que esos países en desarrollo puedan desplegar para favorecer el acceso de sus exportaciones al mercado de los Doce y, por el otro, de la dinámica economica que genere el MUE en

\footnotetext{
${ }^{23}$ Por ejemplo, la factibilidad de ampliar el funcionamiento del Banco Europeo de Inversiones a fin de incluil el financiamiento de proyectos latinoarnericanos.
}

la CE y de la eventual agudización de su proteccionismo.

Institucionalmente, el proteccionismo de la $\mathrm{CE}$ tendrá una modificación fundamental a partir de 1993. El MUE presupone una política comercial conjunta, por lo cual los países no podrán aplicar individualmente restricciones nacionales a ciertas importaciones directas de terceros países o cuando tales productos transiten por otros países comunitarios. ${ }^{24}$ Estos obstáculos nacionales se han utilizado especialmente para proteger a sectores "sensibles" como los textiles, el vestido, el calzado, la agricultura y el acero, todos los cuales, como ya se observó, son fundamentales para la exportación latinoamericana a la CE. Sin embargo, no está claro si estos beneficios serán o no mayores que los costos que se derivarían de establecer medidas comunitarias homogéneas que sustituyan a las nacionales.

\footnotetext{
24 Por lo tanto, el artículo 115 del Tratado de Roma (Tratado Constitutivo de la Comunidad Económica Europea) debería perder su vigencia.
} 
Entre otras, las restricciones más frecuentes que enfrentan tales sectores son las cuotas, el respeto de "precios básicos de importación", que pueden utilizarse para imponer medidas antidumping, y los acuerdos de restricción voluntaria de exportaciones. La CE puede verse inducida a aplicar de manera más intensiva esos instrumentos proteccionistas tras el establecimiento del MUE (Koopmann y Scharrer, 1989).

Tales medidas están en el límite mismo de la legalidad del GATT, ya que contravienen el espíritu aunque no la letra del Acuerdo General. Por ello, son conocidas como "medidas de zona gris" y objeto de negociación en el tema de las salvaguardias de la Ronda Uruguay. Otros instrumentos que preocupan son principalmente las reglas de contenido local, los acuerdos de reciprocidad y el uso abusivo que pudiera hacerse del "nuevo instrumento de política comercial". ${ }^{25} \mathrm{Si}$ la Ronda Uruguay fracasa, se incentivaría la estructuración de megabloques comerciales. En ese escenario, la $\mathrm{CE}$, y no solamente ella, podría cerrar sus fronteras, elevando su proteccionismo de manera insospechada.

Empero, también el proteccionismo comunitario podría aumentar con el MUE si la Ronda Uruguay concluyera satisfactoriamente. Como ya se observó, en términos de la $\mathrm{CE}$ en su conjunto, la cantidad de empresas declinaría en casi todos los sectores productivos (Smith y Venables, 1988). Más aún, es un hecho que los países de menor desarrollo relativo de los Doce enfrentarán con el MUE una situación muy crítica en ciertas áreas económicas que compiten directamente con las exportaciones latinoamericanas. En efecto, un estudio reciente de la CE seffala que los rubros que más se verán afectados en Grecia y Portugal son los textiles y los tejidos de punto, la industria alimenticia y los productos metálicos (Instituto de Estudios Económicos, 1991). Todos ellos son sectores tradicionales, con uso intensivo de mano de obra, y su importancia puede ejemplificarse por la industria textil, que proporciona $9 \%$ de los empleos del sector manufacturero a nivel comunitario, pero más de $23 \%$ de los de Grecia y Portugal (CEPAL, 1992a). Luego, no sería sorprendente que esas naciones tratasen de obtener protección ante terceros países al establecerse el MUE.

Es importante agregar que no sólo cabría esperar un incremento del proteccionismo en los sectores "sensibles" tradicionales, sino también en otros nuevos que podrían surgir como consecuencia de un eventual ajuste económico que, como ya se observó, tiene muchas probabilidades de ocurrir. Ello plantearía serias interrogantes respecto de las estimaciones de beneficios que América Latina y el resto de los países en desarrollo obtendrían con el MUE, basadas en metodologías que suponen que el grado de protección de la CE se mantendrá estable. ${ }^{26}$

Por otra parte, también preocupan las nuevas disposiciones comunes que emanarán de la eliminación de las fronteras técnicas nacionales que han impedido la libre circulación de los bienes a nivel comunitario. Se trata principalmente de estándares de producción, etiquetado y embalaje, procedimientos de certificación de calidad y marcas, normas de seguridad y protección del consumidor y reglamentaciones ambientales, fitosanitarias y veterinarias. ${ }^{27} \mathrm{De}$ acuerdo con la Conferencia de las Naciones Unidas sobre Comercio y Desarrollo (UNCTAD), la mayor parte de estas medidas son consideradas barreras no arancelarias al comercio.

Nadie duda de que será más fácil y entrañará menores costos y riesgos relacionarse con cada uno de los países de la CE a partir de un esquema único de normas y exigencias comerciales y económicas, en lugar de negociar individualmente con cada una de las doce naciones que componen ese esquema de integración. Sin embargo, es muy probable que la armonización de esas disposiciones se haga en función de las legislaciones nacionales más estrictas, lo que implicará en el corto plazo mayores dificultades para el acceso de ciertos productos latinoamericanos al mercado. Por lo tanto, sería útil que la CE otorgara un período adecuado para permitir que estos países, según su nivel de desarrollo, se adapten a las nuevas normas. Además, esto podría complementarse con un apoyo integral significativo en materia de difusión de información a los operadores económicos. ${ }^{28}$

Es un hecho que las preferencias de los consumidores europeos se inclinan cada vez más hacia productos de mayor calidad, debido a que su nivel de

\footnotetext{
25 Tal instrumento permite a los empresarios privados comunitarios recurrir directamente a la Comisión para solicitar medidas de protección en contra de importaciones que harían uso de "prácticas comerciales desleales".

${ }^{26}$ Un ejemplo de este tipo de estimaciones figura en Page, 1990.

27 En 1993 los países de la $\mathrm{CE}$ deberán reconocer como equivalentes las normas de los otros, con la excepción transitoria de las relativas a la salud o a la seguridad de los ciudadanos.

${ }^{2 \pi}$ Este apoyo podría brindarse a través del programa conjunto que están elaborando la Secretaría Permanente del Sistema Económico Latinoamericano (SELA) y la Comisión de las Comunidades Europeas, que pretende evaluar el impacto de la armonización de las normas técnicas comunitarias sobre las exportaciones latinoamericanas,
} 
vida, reflejado básicamente por un alto y creciente ingreso disponible, les permite prestar atención a aspectos relacionados con la salud y el medio ambiente. Una expresión de este fenómeno es la legislación comunitaria más estricta en materia ambiental. Así, se espera que algunas industrias "chimenea" de la $\mathrm{CE}$, especialmente las elaboradoras de minerales que son consideradas contaminantes, se trasladen a América Latina (Grandi, 1991). ${ }^{29}$ "En consecuencia, América Latina está en posición de beneficiarse no sólo de un incremento en sus exportaciones de minerales a la CE, sino también de ventas con mayor valor agregado" (IRELA, 1991, p. 38).

Tal punto de vista, que tiene en cuenta únicamente los beneficios de corto plazo para América Latina, no contempla ni la necesidad de un desarrollo ecológicamente sustentable en esos países ni el hecho de que la protección del medio ambiente es una responsabilidad mundial. Además, los supuestos beneficios para el "basurero" latinoamericano podrían no concretarse, dado que la CE va a mantener su sistema de progresividad arancelaria y que las normas ecológicas comunitarias se extenderán también a las importaciones, como se espera que ocurra, por ejemplo, con las maderas tropicales latinoamericanas (Grabendorff, 1992, p. 230).

En todo caso, América Latina deberá enfrentar el desafío de responder a estas nuevas exigencias de la demanda internacional, diversificando su estructura exportadora con el apoyo de políticas comerciales más enérgicas, y realizando las inversiones necesarias para acrecentar la competitividad y calidad de sus productos a través de la aplicación de modelos económicos sustentables en materia social y ambiental. No obstante, es vital que esas normas funcionen con transparencia y en una perspectiva no proteccionista. Lamentablemente, nada garantiza que la $\mathrm{CE}$ aplicará tales medidas sin discriminación. Es en función de esta inquietud que un Secretario de Estado Adjunto para Asuntos Económicos y Comerciales de los Estados Unidos afirmó "nuestra "línea de fondo" en esta área crítica es la transparencia" (McAllister, 1989, p. 20).

Todo lo anterior indica que probablemente se incremente el proteccionismo no arancelario de la CE como consecuencia del funcionamiento del MUE. En

${ }^{29}$ No obstante, el traslado de empresas contaminantes de países desarrollados a países en desarrollo es un fenómeno que aún no está to suficientemente avalado por pruebas empiricas (Dean, 1992). ese marco, la "fortaleza europea", total o parcialmente materializada, generaría para América Latina costos superiores a los del resto del mundo. Sin embargo, como se examinó en la sección de I este documento, ambos impactos serían menores en la hipótesis del "castillo europeo", es decir, en un escenario donde el proteccionismo no se agudice. En tal caso, y por las mismas razones anteriores, también el costo para los países latinoamericanos sería mayor que para el resto del mundo.

\section{Efectos por sectores}

La demanda de la mayoría de los productos agrícolas es poco elástica tanto en relación al precio como al ingreso. Por lo tanto, ni la reducción de los precios ni el aumento del ingreso en la CE, ambos efectos esperados, provocarán incrementos importantes de la demanda o de las importaciones comunitarias. Menos aún si una proporción apreciable de los bienes que América Latina exporta a ese mercado compite directamente con la producción europea o la de los países ACP, que están protegidas, por la PAC y la Convención de Lomé.

Entre los rubros que podrían verse más afectados se cuentan el banano, las maderas tropicales, el azúcar, el cacao y los productos agrícolas de clima templado, como los cereales, la soya y sus subproductos. Ello perjudicaría a casi todos los países latinoamericanos, aunque con intensidades distintas. Por otra parte, un producto para el cual podría esperarse un efecto positivo es el café. Sin embargo, beneficiaría a los países centroamericanos más que, por ejemplo, a Brasil y Colombia, por cuanto el consumo comunitario probablemente se oriente hacia las mezclas de mejor calidad del café centroamericano (Grabendorff, 1992, p. 229).

También los minerales y metales tienen una demanda poco elástica en relación al precio y al ingreso, por lo que no cabe prever un incremento significativo de las importaciones comunitarias de estos bienes. Más aún, como uno de los principales objetivos del MUE es que las empresas europeas logren incorporar innovaciones tecnológicas para obtener mayores niveles de eficiencia, se espera que como consecuencia de la introducción de nuevos procesos productivos se reduzca el consumo de minerales y metales.

En esa dirección apunta la política tecnológica de la CE, que pretende, entre otros objetivos, fomentar la sustitución de los materiales tradicionales por otros menos costosos, como por ejemplo la fibra ópti- 
ca y el reciclaje de residuos. En definitiva, "entre los productos con posibles problemas o que tendrán un impacto negativo se encuentran el mineral de hierro, concentrados y minerales no procesados, como metales no ferrosos, cobre, bauxita ..." (Grandi, 1991, p. 100). Además, como se espera que la CE mantenga la progresividad arancelaria, las perspectivas para los productos más elaborados tampoco son optimistas. Los países latinoamericanos que podrían ver más afectada su exportación de minerales y metales a la CE son Bolivia, Brasil, Chile, Perú y Venezuela.

Las perspectivas para el petróleo son aún más desalentadoras. "El 17 de diciembre de 1991, los representantes de los Estados Miembros de la Conferencia sobre Seguridad y Cooperación en Europa, las repúblicas de la ex URSS y Australia se reunieron en el marco de la 'Conferencia de La Haya sobre la Carta Europea de la Energía', cuyo objetivo final es crear en Europa un mercado de la energía basado en las ricas reservas de petróleo y gas de la antigua URSS. La combinación de suministros del Este e inversiones del Oeste podría conducir a una eventual autonomía europea en el sector de la energía, con lo cual las exportaciones latinoamericanas de combustibles perderían gran parte del mercado europeo" (IRELA, 1992, pp. 36-37). Además, la política energética de la $\mathrm{CE}$ entraña el uso de tecnologías que ahorran combustibles o de sustitutos del petróleo. Por lo tanto, los efectos para Ecuador, México y Venezuela serían importantes.

Por su parte, la demanda de manufacturas es altamente elástica respecto del ingreso y los precios. Luego, cabe esperar que el consumo de bienes manufacturados aumente, lo que no necesariamente incrementará las importaciones extracomunitarias de tales productos, debido a que con el muE la producción de los Doce será particularmente más competitiva en este sector. Así, y aunque el proteccionismo comunitario no se modifique, las perspectivas para América Latina no son optimistas. La progresividad arancelaria y las barreras no arancelarias existentes son elementos suficientes, tal como lo fueron en el pasado, para ofrecer un firme obstáculo al acceso de esos bienes latinoamericanos a la CE.

De hecho, sólo tres productos manufacturados pesan más de $5 \%$ en el total de las colocaciones de tangibles de esa región en desarrollo en el mercado comunitario: el calzado, los textiles y los artículos de cuero, sectores en los cuales ha habido una pérdida progresiva de la importancia latinoamericana en las importaciones de los Doce. Además, se espera que en el futuro la competencia de Europa oriental acelere esta declinación (Grabendorff, 1992).

Con respecto a los servicios, cabe destacar que América Latina difícilmente podría beneficiarse de la apertura europea en ese sector, ya que no ha alcanzado aún competitividad internacional suficiente en tal rubro. Una de las muy pocas excepciones que se registran es el turismo, actividad que a la larga podría reportar ciertos beneficios a América Latina, como consecuencia de los mayores ingresos monetarios de que dispondrán los ciudadanos de la CE.

En conclusión, todo indicaría que las consecuencias del mUE en el comercio de América Latina serán, al menos en el corto y mediano plazo, adversas. Y no sólo en lo que tiene relación con el territorio comunitario, sino también respecto del resto del mundo, porque la CE también mejorará su posición competitiva en los mercados internacionales, incluyendo el latinoamericano.$^{30}$ Luego, el desafío es inevitable para la región latinoamericana: realizar las transformaciones estructurales que le permitan alcanzar una inserción más plena en la economía mundial, ampliando las opciones comerciales para diversificar al máximo los productos y mercados de exportación. Aun así, no debe descuidarse el estrechamiento de los vínculos económicos con la CE. Para ello será necesario reforzar la capacidad negociadora de América Latina, dándole un mayor impulso a la integración regional y más apoyo a las instancias de diálogo político y económico con la CE.

\section{Otras consideraciones}

Debe tenerse en cuenta que las conclusiones anteriores están basadas en un enfoque que se concentra en los efectos que el MUE generaría en el corto y mediano plazo. Sin embargo, es posible visualizar para el largo plazo un escenario más optimista, determinado por tres factores. El primero sería que el mercado de la $\mathrm{CE}$ superara las vicisitudes del ajuste económico en el contexto de políticas macroeconó-

\footnotetext{
30 Por lo tanto, cabría esperar una reducción del precio de las importaciones latinoamericanas procedentes de la CE. Sin embargo, ese beneficio podría ser sobrepasado, por una parte, por los costos que se derivarían de la pérdida de competitividad de las exportaciones de América Latina en relación a las comunitarias en los mercados externos y, por otra, por la eventual caída de los términos de intercambio para los principales productos latinoamericanos de exportación, como consecuencia de una mayor oferta internacional provocada por los productos europeos que compiten con los de América Latina, en particular, los agrícolas de zona templada.
} 
micas más coherentes. Es muy probable que la maduración del MUE avance hacia una reestructuración dinámica de las ventajas comparativas entre sus países miembros y permita la consecución de niveles de eficiencia productiva suficientes para que sus productos sean más competitivos internacionalmente. ${ }^{31}$ En consecuencia, no se justificaría un proteccionismo de la $\mathrm{CE}$ de la envergadura del actual o del previsible para el mediano plazo. Además, a la larga se manifestarian los beneficios dinámicos derivados de la profundización del proceso de integración europeo, con las consiguientes economías externas para el resto del imundo.

El segundo factor estaría basado en el supuesto de que el sistema multilateral de comercio evolucione hacia una tendencia de mayor apertura y competitividad, donde las regulaciones internacionales se orienten a lograr no sólo un funcionamiento más transpa-

31 Todo ello en un contexto de reordenamiento político-económico de Europa, que entrañe no sólo la feliz resolución de ciertos conflictos políticos en el seno de la CE y la profundización del acuerdo rente del comercio mundial de bienes, sino también de los servicios y flujos financieros. Para ello es evidente que la Ronda Uruguay debería llegar a un término aceptable dentro de un plazo razonable.

Por último, en relación con los beneficios para América Latina, será crucial que los países de la región continúen avanzando por la senda de la reestructuración productiva en un contexto de apertura externa y estabilidad política y económica, que les permita desarrollar las ventajas comparativas dinámicas necesarias para ocupar los nichos que ofrecen los mercados internacionales. Es preciso que la estructura exportadora latinoamericana vaya evolucionando dinámicamente según las cambiantes condiciones de la demanda mundial, que exige la aplicación de un modelo de desarrollo de largo plazo que sea sustentable desde el punto de vista técnico, económico, social y ambiental. de libre comercio con los países de la AELi, sino también un esquema económico europeo más integrado y de carácter prácticamente continental.

\section{Bibliografía}

Baldwin, R. (1989): The growth effects of 1992, Economic Policy, $\mathrm{N}^{\circ}$ 9, Cambridge, Gran Bretaña, Cambridge University Press, octubre.

Barón, E, (1991): Una atracción no correspondida, Pensamiento iberoamericano. La nueva Europa y el futuro de América Latina, volumen extraordinario, Madrid, Instituto de Cooperación Iberoamericana (ICI)/Sociedad Estatal Quinto Centenario.

Butelmann, A. y M.P. Campero (1992): Medición del escalonamiento arancelario de las exportaciones chilenas a los EE.UU., Estrategia comercial chilena para la década del 90. Elementos para el debate, A. Butelmann y P. Meller (eds.), Santiago de Chile, Corporación de Investigaciones Económicas para Latinoamerica (CIEPLAN).

Cecchini, P. (1988): The European Challenge 1992: The Benefits of a Single Market, Aldershot, Gower Publishing Company Limited.

CEPAL (Comisión Económica para América Latina y el Caribe) (1990a); Europa 1992 y sus consecuencias económicas sobre América Latina, LC/R.918(Sem.59/3), Santiago de Chile, septiembre.

(1990b): ¿Cooperación o divergencia? Hacia una nueva agenda en las relaciones euro-latinoamericanas, LC/R.929(Sem.59/5), Santiago de Chile, octubre.

(1990c): Transformación productiva con equidad, LC/G.1601-P, Santiago de Chile, marzo. Publicación de las Naciones Unidas, $\mathrm{N}^{\circ}$ de venta S.90.II.G.6.

(1992a): La políica contercial de la Comunidad Econó- mica Europea despuér de 1992: implicaciones para América Latina, LC/R.1139, Santiago de Chile, abril.

(1992b): Las barreras no arancelarias a las exportaciones latinoamericanas en la Comunidad Económica Europea, los Estados Unidos de América y el Japón, LC/R. 1201, Santiago de Chile, octubre.

(1992c): Equidad y transformación productiva: un enfoque integrado, LC/G.1701(SES.24/3), Santiago de Chile, febrero.

CET (Centro de las Naciones Unidas sobre las Empresas Transnacionales) (1989): The CTC Reporter, $\mathrm{N}^{\circ} 27$, Nueva York, Naciones Unidas, primavera.

Comisión de las Comunidades Europeas (1988): The economics of 1992. An assessment of the potential economic effects of completing the internal market of the European Community, European Economy, № 35, Bélgica, marzo.

(1989): European Econony, No 39, Bélgica, marzo.

(1992): Suplemento-objetivo 92, $\mathrm{N}^{\circ} 9$, Bélgica, noviembre.

Dean, J. (1992): Trade and environment: a survey of the literature, Patrick Low (ed.), International Trade and the Environment, World Bank Discussion Papers, $N^{\circ} 159$, Washington, D.C.

Delors, J. (1991): Primero reforzar, después ampliar, Pensamiento iberoamericano. La mueva Europa y el futuro de América Latina, volumen extraordinario, Madrid, ICI/Sociedad Estatal Quinto Centenario.

Dormbusch, R. (1989): Europe 1992: macroeconomic implications, Brookings Papers on Economic Activity, $\mathrm{N}^{\circ} 2$, Washington, D.C., Brookings Institution. 
Emerson, M. y otros (1988); The Economics of 1992: the EC Commission's Assessment of the Economic Effects of Completing the Internal Market, Oxford, Oxford University Press.

Emmerij, L. (1990); Europe 1992 and the developing countries: conclusions, Journal of Common Market Studies, vol. XXIX, $\mathrm{N}^{\mathrm{a}}$ 2, volumen especial, Oxford, Basil Blackwell, diciembre.

Grabendorff, W. (1992): European integration: implications for Latin America, Colin I. Bradford (ed.), Strategic Options for Latin America in the 1990s, París, Centro de Desarrollo de la Organización de Cooperación y Desarrollo Económicos (OCDE).

Grandi, J. (1991): El impacto del mercado único europeo para América Latina: obstáculos y oportunidades, Integración latinoamericana, $\mathrm{N}^{\circ} 167$, Buenos Aires, Instituto para la Integración de América Latina (INTAL), mayo.

Instituto de Estudios Económicos (1991): El impacto del mercado único en el sur de Europa, Revista del Instituto de Estudios Economicos, $\mathbf{N}^{\circ} 3$, Madrid.

IRELA (Instituto de Relaciones Europeo-Latinoamericanas) (1991): El mercado único europeo y América Latina, Dossier, $\mathrm{N}^{\circ} 34$, Madrid, septiembre.

(1992): América Lasina y Europa: hacia el año 2000, Dossier, $\mathbb{N}^{\circ} 40$, Madrid, septiembre.

Izam, M. (1991): Europa 92 y la economla latinoamericana, Revista de la CEPAL, $N^{\circ} 43, \mathrm{LC} / \mathrm{G} .1654-\mathrm{P}$, Santiago de Chile, abril.
Koopmann, G. y H. Scharter (1989): EC trade policy beyond 1992 , Intereconomics, vol. $24, \mathrm{~N}^{\circ} 5$, Hamburgo, Verlag Weltarchiv GMBH, septiembre-octubre.

McAllister, E, (1989): Una perspectiva norteamericana sobre la CE-90, Perspectivas económicas, $\mathrm{N}^{\circ} 69$, Washington, D.C. Agencia de Informaciones de los Estados Unidos (USIA).

Page, S. (1990): Some Implications of Europe 1992 for Developing Countries, Londres, Consejo de Desarrollo de Ultramar, diciembre.

Peck, M.J. (1989): Industrial organization and the gains from Europe 1992, Brookings Papers on Economics Activity, $\mathrm{N}^{\circ} 2$, Washington, D.C., Brookings Institution.

Sáez, S. (1992): Chile y la Comunidad Económica Europea, A. Butelmann y P. Meller (eds.), Estrategia comercial chilena para la década del 90 . Elementos para el debate, Santiago de Chile, CIEPLAN.

SELA (Sistema Económico Latinoamericano) (1992): Reunión sobre comercio entre el Gripo de Rio y la Comunidad Econó. mica Europea. Nota de la Secretarla Permanente, Caracas, octubre.

Smith, A. y A. Venables (1988): An assessment based on a formal model of imperfect competition and economies of scale, Research on the Cost of Non-Europe. Basic Findings, vol. 2, Luxemburgo, Comisión de las Comunidades Europeas, Oficina de Publicaciones Oficiales. 